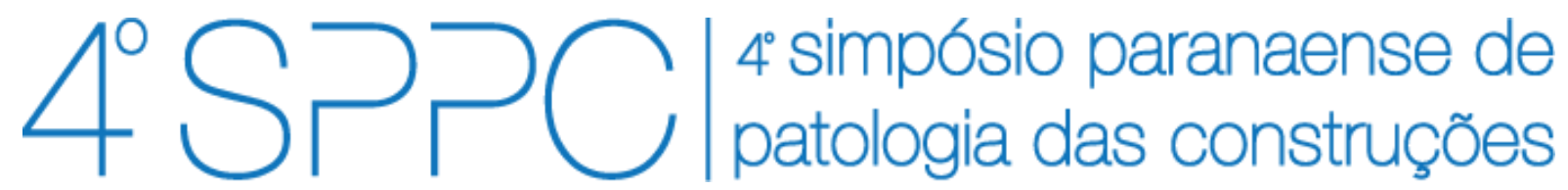

ISSN 2526-7248 artigo n. 4SPPC128, pp. 261-270, 2019

\title{
Degradação do concreto armado por ácido sulfúrico biogênico do reator RALF de uma Estação de Tratamento de Esgoto (ETE)
}

\author{
Godinho, Jayson Pereira ${ }^{1}$; Medeiros, Marcelo Henrique Farias de ${ }^{2}$ \\ ${ }^{1}$ Eng. Ambiental e de Segurança do Trabalho, Mestre em Ciência e Tecnologia \\ Ambiental (PPGCTA) pela UTFPR, Doutorando em Eng. de Construção Civil \\ (PPGECC) pela UFPR, jayson.godinho.eng@gmail.com \\ ${ }^{2}$ Eng. Civil, Mestre e Doutor em Eng. Civil pela Universidade de São Paulo (USP), \\ Docente na UFPR, Departamento de Construção Civil (DCC), \\ marcelo.ufpr@gmail.com
}

Resumo: As estações de tratamento de esgoto são exemplos de estruturas submetidas a ambientes industriais altamente agressivos. Diante disto, o objetivo deste trabalho é avaliar o grau de contaminação da estrutura de concreto de uma ETE localizada em Curitiba-Brasil, exposta por cerca de 20 anos em um ambiente dentro do processo de tratamento de efluentes. Foram coletas amostras de uma laje do reator RALF e outros amostras da superfície da parede de concreto do mesmo reator. Foram realizados ensaios de MEV/EDS, resistência à compressão uniaxial e potencial de corrosão das armaduras expostas. Os resultados indicam que 0 ataque ao concreto inspecionado ocorre na superfície, avançando em profundidade ao longo do tempo. Além disso, a área mais atacada é a que ocorre a variação do esgoto ao longo do dia, com intensa degradação da superfície do concreto causada pela descalcificação de $\mathrm{C}-\mathrm{S}-\mathrm{H}$, resultando na formação de gesso como produto final do mecanismo de degradação.

Palavras-chave: Concreto armado, Patologia, Durabilidade

\begin{abstract}
Sewage treatment plants are examples of structures subject to highly aggressive industrial environments. Therefore, the objective of this work is to evaluate the degree of contamination of the concrete structure of an ETE located in CuritibaBrazil, exposed for about 20 years in an environment within the effluent treatment process. Samples were collected from a slab of the RALF reactor and other samples from the concrete wall surface of the same reactor. SEM/EDS tests, uniaxial compression strength and corrosion potential of the exposed reinforcement were performed. The results indicate that the attack on the inspected concrete occurs on the surface, advancing in depth over time. Moreover, the most attacked area is the one that occurs the variation of the sewage throughout the day with intense degradation of the surface of the concrete caused by the decalcification of $\mathrm{C}-\mathrm{S}-\mathrm{H}$, resulting in the formation of gypsum as the final product of the mechanism of degradation.
\end{abstract}

Keywords: Reinforced concrete, Pathology, Durability. 
GODINHO, J. P.; MEDEIROS; M. H. F., DEGRADAÇÃO DO CONCRETO ARMADO POR ÁCIDO SULFÚRICO BIOGÊNICO DO REATOR RALF DE UMA UMA ESTAÇÃO DE TRATAMENTO DE ESGOTO (ETE). $4^{\circ}$ Simpósio Paranaense de Patologia das Construções (40 SPPC), artigo 4SPPC128, pp. 261 - 270, 2019. DOI: 10.4322/2526-7248.048

\section{Introdução}

As estações de tratamento necessárias para o saneamento das cidades são compostas por reatores biológicos e outros elementos estruturais que geralmente são construídos com concreto armado. O efluente proveniente do esgoto é rico em sulfatos e isso gera um complexo meio de alta agressividade a uma estrutura de concreto armado [1,2].

Em todo o mundo, os sistemas de tratamento de águas servidas municipais estão expostos a degradação do concreto por ácido sulfúrico biogênico, que tende a comprometer a integridade das estruturas, necessitando de dispendiosos reparos provocados por falhas prematuras da infraestrutura necessária ao tratamento de esgoto [2,3]. Na Bélgica, por exemplo, este tipo de degradação representa um custo de $10 \%$ do total dos gastos com o tratamento de água de esgoto [4]. Nos Estados Unidos, estima-se que seja necessário um investimento anual de até US \$ 21 bilhões para novas infraestruturas para o tratamento de esgoto sanitário, mas que os custos anuais de operação e manutenção excedam US \$ 25 bilhões [5,6].

Na Europa, na maioria dos países industrializados, os sistemas de esgotos têm mais de 40 anos e agora exigem grande reabilitação. Assim, a necessidade de reabilitar partes da rede de esgoto nas grandes cidades e construir novas estruturas, leva as instituições a considerar as melhores maneiras de construir instalações sanitárias sustentáveis e otimizar a gestão do saneamento ambiental [7].

Desse modo, estudos focados em entender o mecanismo de degradação que envolve este ambiente agressivo ao concreto são importantes para o avanço da fronteira do conhecimento, oferecendo mais subsídios para o meio técnico produzir especificações de materiais mais adequados e capazes de gerar estruturas com elevada durabilidade, apesar da alta agressividade que ocorre nas estações de tratamento de esgoto.

Este trabalho está focado na inspeção realizada em uma estação de tratamento de esgoto localizada na cidade de Curitiba, compreendendo avaliações mecânicas, químicas, eletroquímicas e dos produtos formados provenientes da degradação do concreto nestas condições. A principal informação a ser produzida irá responder se o ataque por ácido sulfúrico biogênico, característico das estações de tratamento de esgoto, tende a degradar o concreto superficialmente ou se o concreto é agredido como um todo ao longo de sua profundidade.

\section{Metodologia}

Este trabalho foi desenvolvido em uma estação de tratamento de esgoto sanitário da cidade de Curitiba-PR. Esta estação de tratamento tem cerca de 20 anos em operação e encontra-se com concreto em processo de desagregação superficial, apresentando-se como uma espécie de descamação, sendo possível sua remoção, com as mãos. Na Figura 1 são ilustradas as áreas inspecionadas que ficaram concentradas em um Reator Anaeróbio de Lodo Fluidizado (RALF) que se encontrava em pleno funcionamento na época da coleta das amostras. Foram coletadas amostras do material desagregado e solto na superfície da parede do tanque do reator de forma 
manual e 7 amostras (testemunhos) transpassando a laje, com o emprego de uma extratora com broca de ponta diamantada com 46 mm de diâmetro (Figura 1a).

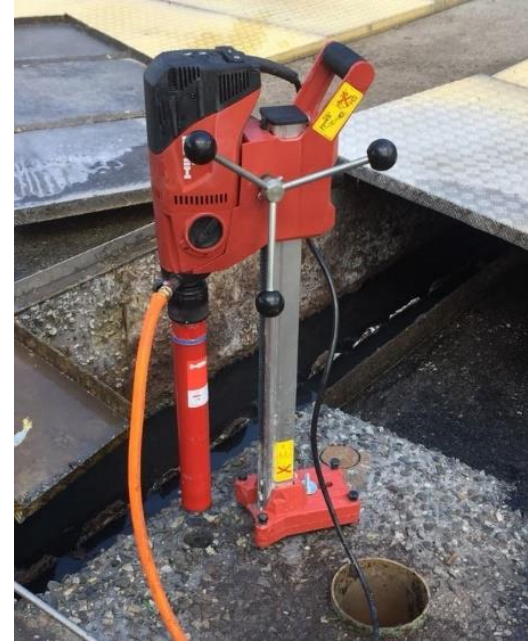

(a)

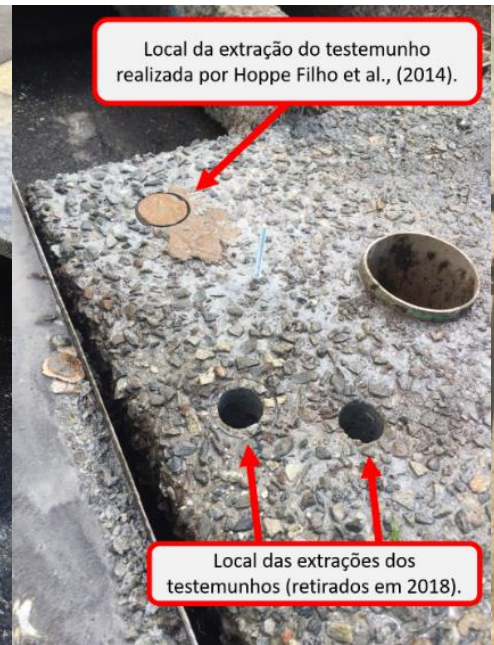

(b)

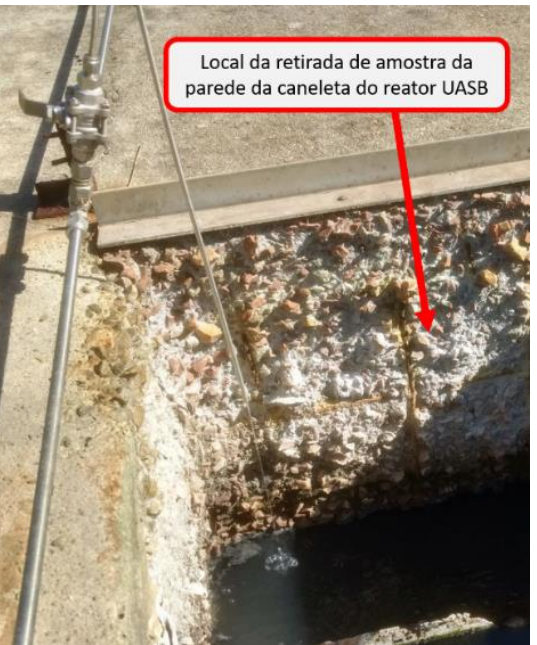

(c)

Figura 1: Locais de coleta das amostras de concreto do reator RALF: (a) Extração dos testemunhos da laje; (b) Laje sem contato direto com o efluente; (c) Parede do reator com contato direto com o efluente.

\subsection{Profundidade de neutralização}

Logo após as extrações dos testemunhos das lajes do reator, foi aspergida uma solução contendo $1 \%$ de fenolftaleína, $70 \%$ de álcool etílico e $30 \%$ de água destilada em 4 testemunhos de concreto. Esse procedimento é regido pelas normas BS EN 14630 [8] e RILEM CPC-18 [9] e permite determinar a profundidade de neutralização com o auxílio de um paquímetro (mesmo procedimento para determinação da profundidade de carbonatação). Essa profundidade de neutralização representa a redução do $\mathrm{pH}$ de aproximadamente 12 do concreto saudável, devido ao contato e penetração do ácido sulfúrico em direção ao interior do concreto, para abaixo da faixa de viragem da solução marcadora de fenolftaleína que é de $8,2 \leq \mathrm{pH} \leq 10,0$.

\subsection{Potencial de corrosão das barras de aço carbono do reator RALF}

A avaliação do potencial de corrosão $\mathrm{E}_{\text {corr }}(\mathrm{mV})$ foi realizada com um multímetro ICEL modelo MD-6111 e um eletrodo de referência de cobre-sulfato de cobre $(\mathrm{Cu} / \mathrm{CuSO})_{4}$, seguindo a metodologia (Figura 2) e o critério de avaliação da ASTM C876 [10] e semelhante aos procedimentos realizados por Capraro et al. [11] e Souza et al. [12]. As barras de aço carbono, em que foram realizadas as leituras, foram aquelas localizadas nas paredes das caneletas do reator da Figura 1C e também em outras barras localizadas na lateral da laje onde foram realizadas as extrações dos testemunhos (Figura 1B). 


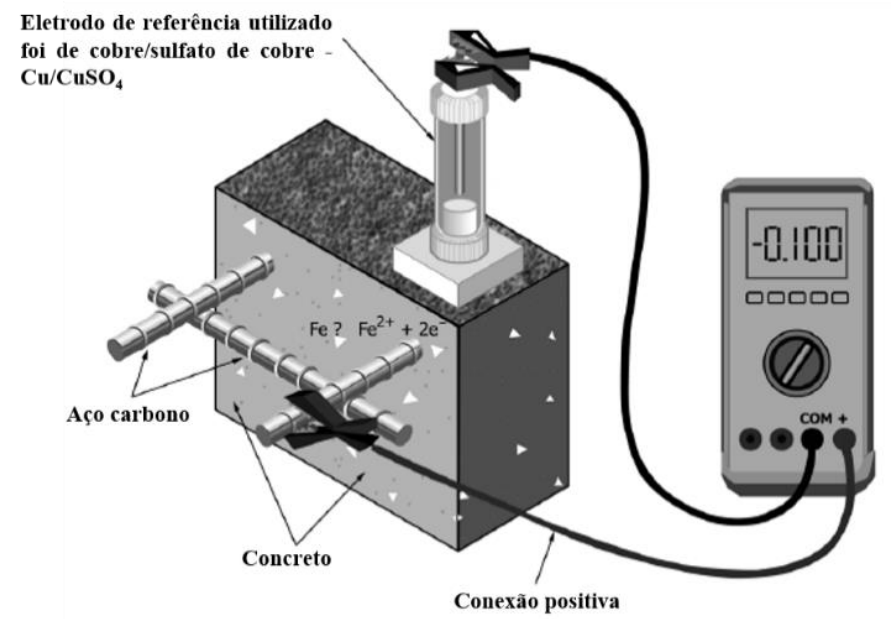

Figura 2: Esquema do ensaio para a realização das leituras de potencial de corrosão. Fonte: Adaptado de ASTM C876 [10].

\subsection{Resistência à compressão axial}

Os 4 testemunhos foram cortados (com dimensões de $46 \mathrm{~mm} \times 100 \mathrm{~mm}$ ) e após esse procedimento foi realizado o capeamento com enxofre em seus topos (Figura 3). 0 ensaio de resistência à compressão uniaxial foi realizado em consonância com as NBR 5739 [13] e NBR 7680-1 [14] com o auxílio de uma prensa modelo MUE-100, da EMIC, com sistema computadorizado modelo TESC-EMIC que já corrige os valores em função da relação altura/diâmetro $(\mathrm{h} / \mathrm{d})(\mathrm{k} 1)$ e do efeito do broqueamento em função do diâmetro do testemunho extraído (k2).

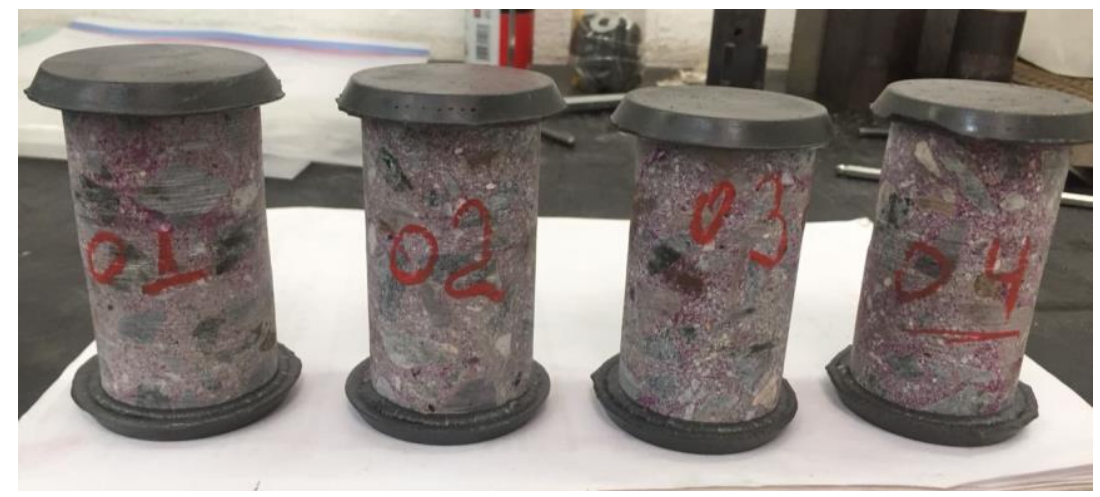

Figura 3: Procedimento de capeamento com enxofre dos testemunhos.

\subsection{Ensaios microestruturais de MEV/EDS}

Para realizar as análises microestruturais do concreto ao longo da profundidade de 1 dos testemunhos, o mesmo foi cortado em 8 discos de espessura variável. No dia anterior a realização das imagens de $\mathrm{MEV}$, as amostras foram coladas com um esmalte, contendo grafite, em stubs metálicos para serem encaixadas no portaamostra, metalizadas com ouro e posteriormente colocadas no interior do microscópio 
para o ensaio. As imagens de microscopia eletrônica de varredura foram obtidas com o auxílio de um microscópio FEG SEM, Tescan, Mira 3, com identificação dos compostos formados pela morfologia dos cristais, auxiliado por microssonda analítica de raios-X Oxford X-Max 50 (EDS), que inferiu a composição química dos compostos por espalhamento de elétrons.

\section{Resultados e discussões}

\subsection{Profundidade de neutralização}

A profundidade de neutralização encontrada com a aspersão de fenolftaleína foi diagnosticada apenas nos topos dos testemunhos de concreto, em uma profundidade aproximada de $5 \mathrm{~mm}$ (Figura 4). Ou seja, o restante da profundidade do testemunho possui $\mathrm{pH}$ superior ao $\mathrm{pH}$ de viragem da solução $(8,2 \leq \mathrm{pH} \leq 10,0)$.

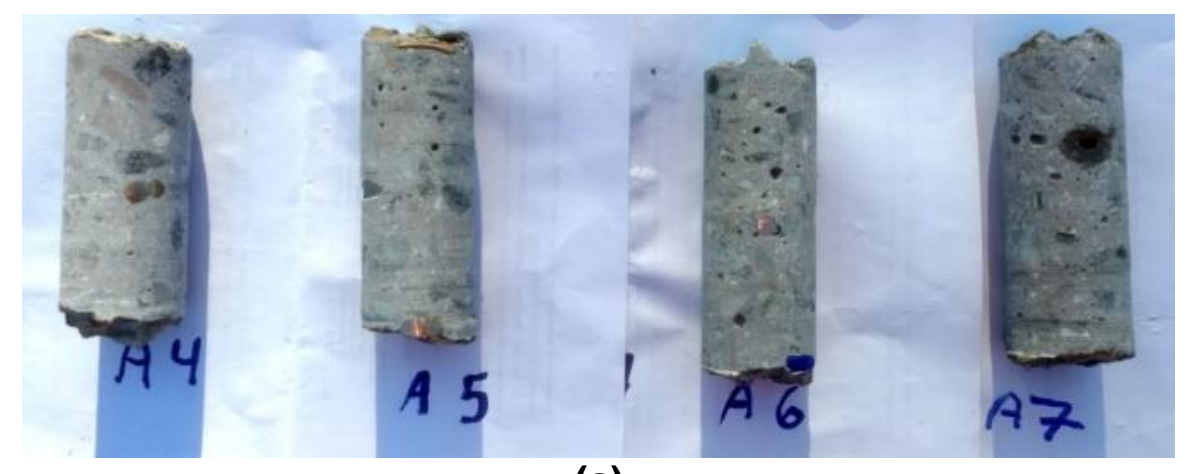

(a)

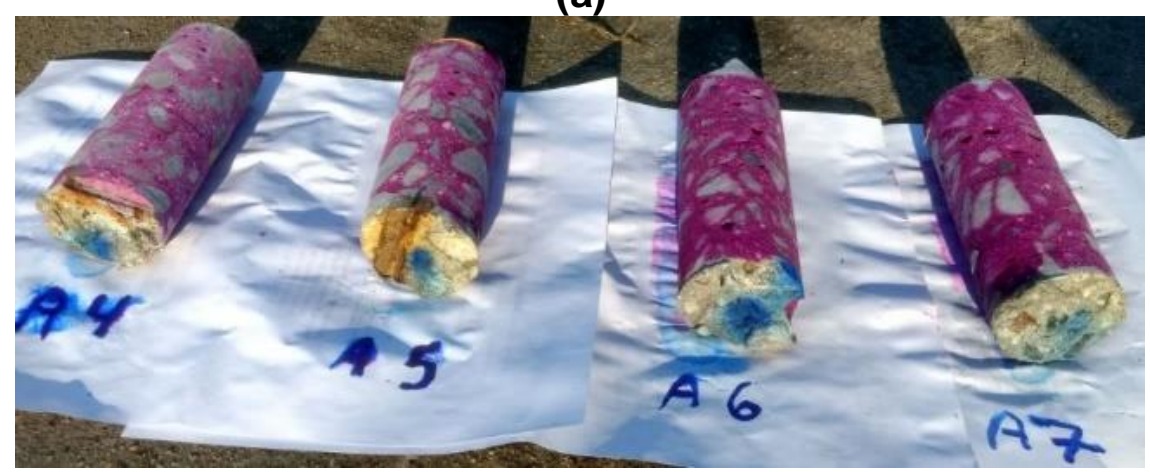

(b)

Figura 4: Ensaio de profundidade de neutralização. (a) antes da aspersão da solução de fenolftaleína; (b) após a aspersão da solução de fenolftaleína.

\subsection{Potencial de corrosão das barras de aço carbono do reator RALF}

Na Figura 5 é apresentado o potencial de corrosão das barras de aço carbono expostas da parede e da laje do reator RALF. 
GODINHO, J. P.; MEDEIROS; M. H. F., DEGRADAÇÃO DO CONCRETO ARMADO POR ÁCIDO SULFÚRICO BIOGÊNICO DO REATOR RALF DE UMA UMA ESTAÇÃO DE TRATAMENTO DE ESGOTO (ETE). $4^{\circ}$ Simpósio Paranaense de Patologia das Construções (40 SPPC), artigo 4SPPC128, pp. 261 - 270, 2019. DOI: 10.4322/2526-7248.048

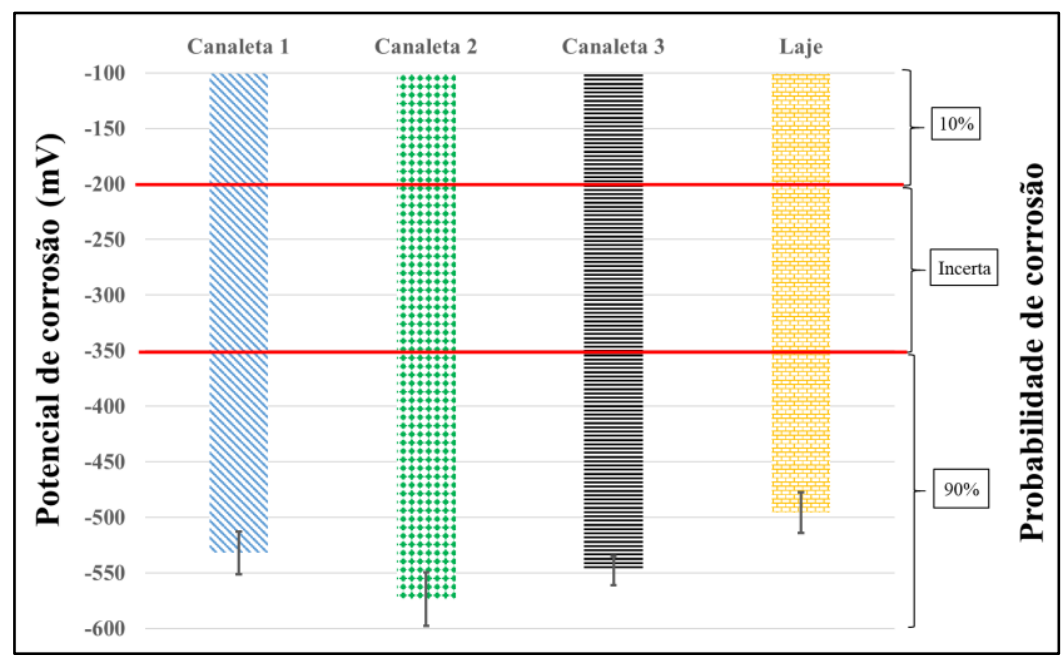

Figura 5: Potencial de corrosão das barras de aço carbono do reator RALF.

Todas as armaduras se encontraram na região de $90 \%$ de probabilidade de corrosão, corroborando com a inspeção visual das barras expostas, que se encontravam com um grau acentuado de oxidação e também das barras internas da laje, com pontos específicos de oxidação.

\subsection{Ensaios microestruturais de MEV/EDS}

Na Figura 6 é apresentada a microestrutura das fatias de 1 dos testemunhos do concreto das lajes da ETE.

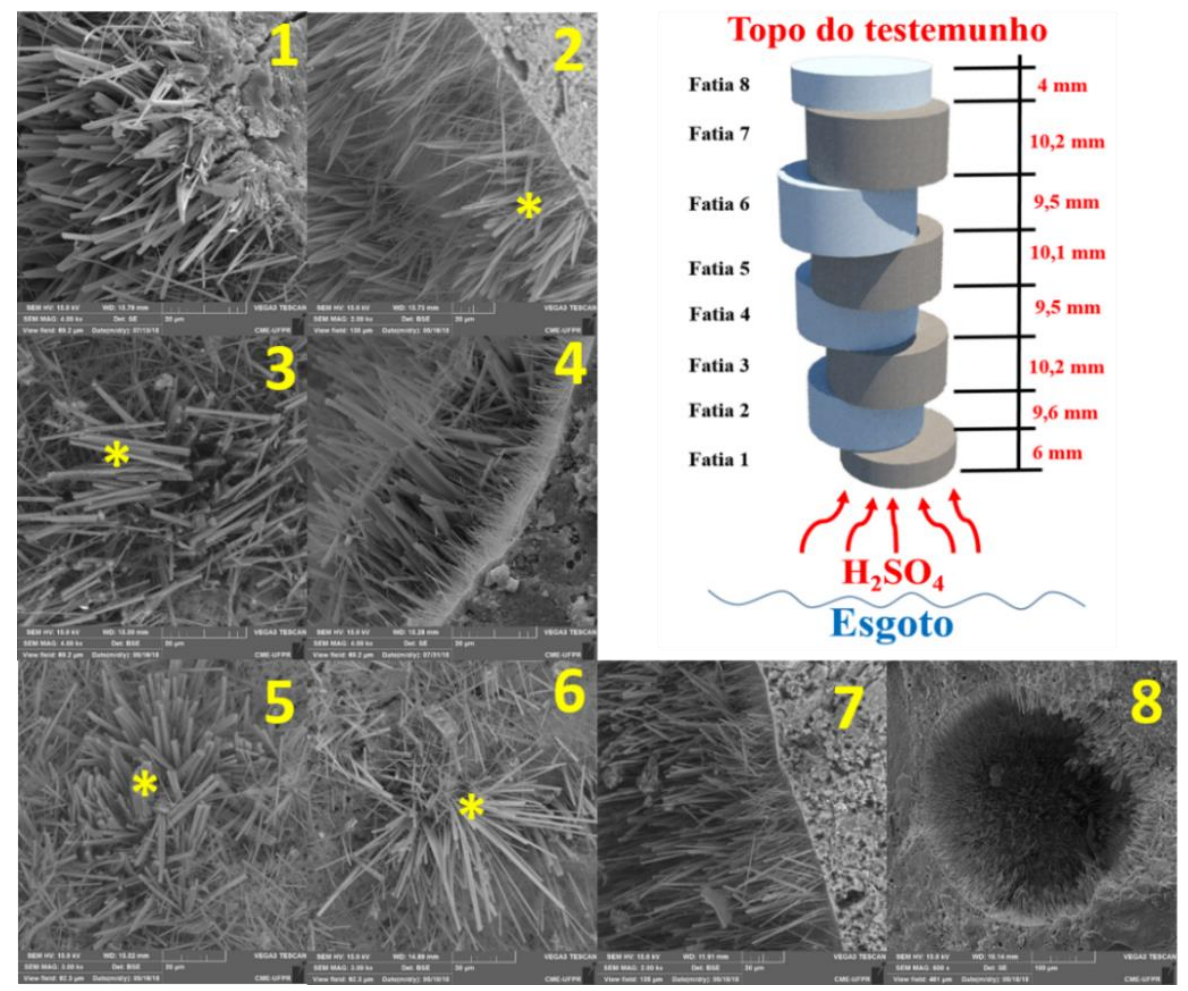

Figura 6: Microscopia eletrônica de varredura (MEV) de cada uma das 8 fatias do testemunho extraído. Obs. Os pontos onde foram realizadas as análises de EDS estão representados por um asterisco $\left({ }^{*}\right)$. 
$\mathrm{Na}$ Tabela 1 são apresentados os resultados da espectroscopia de energia dispersiva (EDS) dos pontos indicados na Figura 6.

Tabela 1: Proporção dos elementos oxigênio, cálcio, enxofre, alumínio e hidrogênio na etringita em relação ao EDS dos pontos indicados na Figura 6.

\begin{tabular}{cccccc}
\hline Elementos & $\begin{array}{c}\text { Percentuais teóricos } \\
\text { dos elementos da } \\
\text { etringita (\%) }\end{array}$ & \multicolumn{4}{c}{$\begin{array}{c}\text { Percentuais dos elementos } \\
\text { encontrados por EDS (\%) após ajuste }\end{array}$} \\
\cline { 2 - 6 } O & 63,74 & 57,2 & 50,9 & 57,9 & 55,8 \\
Ca & 19,13 & 26,3 & 32,4 & 26,5 & 27,9 \\
S & 7,67 & 8,2 & 7,3 & 7,2 & 8,5 \\
Al & 4,30 & 5,1 & 4,8 & 5,0 & 5,2 \\
H & 5,14 & - & - & - & - \\
\hline
\end{tabular}

Foi possível identificar a presença de etringita pelo ensaio de MEV/EDS em todas as 8 fatias do testemunho extraído da laje do reator RALF, indicando assim, que o enxofre penetrou no concreto da laje ao longo de toda a sua profundidade. Contudo, a presença de gipsita somente foi possível ser observada na parte externa das fatias 1 e 8, conforme é mostrado na Figura 7 e corroborado pelo EDS (Tabela 2).

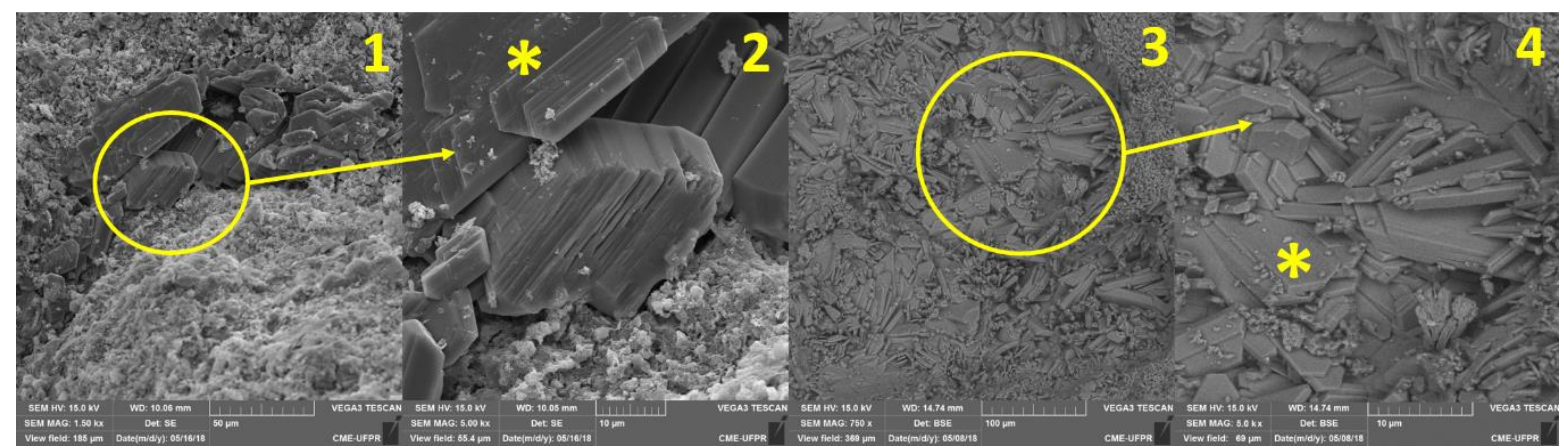

Figura 7: Microscopia eletrônica de varredura (MEV) das fatias 1 e 8 do testemunho extraído. Legenda: 1 e 2 - fatia 1; 2 e 4 - fatia 8. Obs. Os pontos onde foram realizadas as análises de EDS estão representados por um asterisco $\left(^{*}\right)$.

Tabela 2: Proporção dos elementos oxigênio, cálcio, enxofre e hidrogênio na gipsita em relação ao EDS dos pontos indicados na Figura 7.

\begin{tabular}{cccc}
\hline Elementos & $\begin{array}{c}\text { Percentuais teóricos } \\
\text { dos elementos da } \\
\text { gipsita (\%) }\end{array}$ & $\begin{array}{c}\text { Percentuais dos } \\
\text { elementos encontrados } \\
\text { por EDS (\%) }\end{array}$ \\
\hline $\mathbf{O}$ & 55,8 & 51,8 & 47,0 \\
$\mathbf{C a}$ & 23,3 & 20,8 & 19,8 \\
$\mathbf{S}$ & 18,6 & 14,4 & 18,2 \\
$\mathbf{H}$ & 2,3 & - & - \\
\hline
\end{tabular}


Em comparação com as imagens obtidas na parte interna e externa do testemunho, fica claro que as configurações morfológicas são diferentes, com uma maior presença de gipsita na parte externa. Essa diferença indica que a degradação se manifesta de forma distinta e em velocidades diferentes, pois na parte externa do testemunho existe maior disponibilidade de enxofre, oxigênio, umidade e nutrientes para o desenvolvimento das bactérias redutoras de sulfato e consequentemente maior geração de ácido sulfúrico biogênico.

\subsection{Resistência à compressão axial das lajes da ETE}

Na Figura 8 é apresentada a resistência à compressão axial dos 4 testemunhos das lajes do reator RALF.

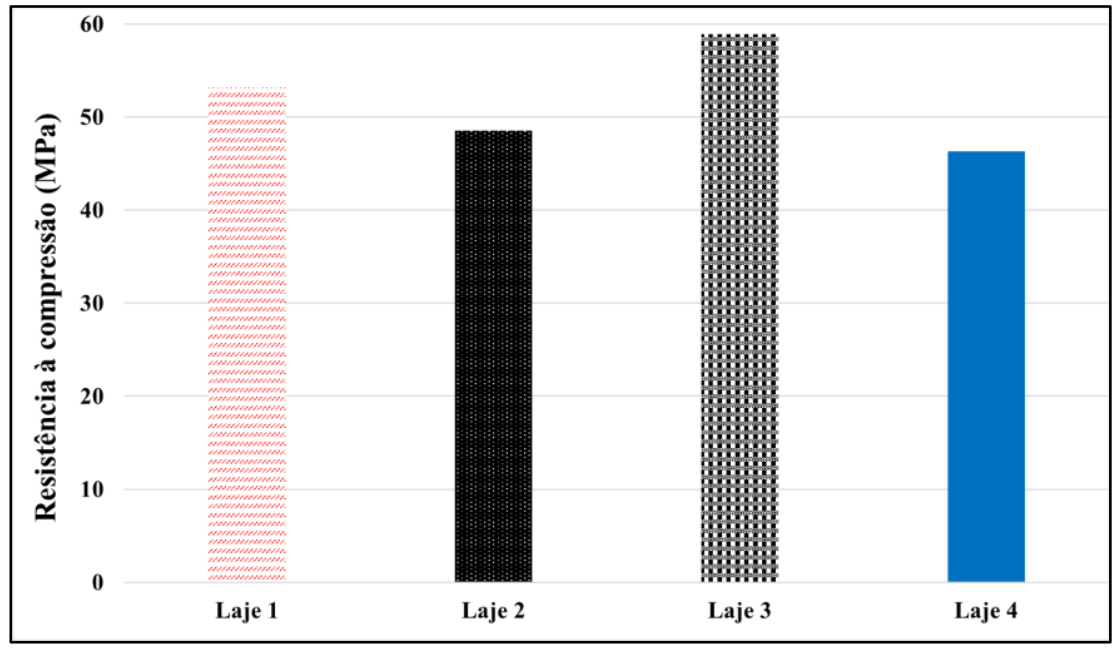

Figura 8: Resistência à compressão axial dos testemunhos das lajes do reator RALF.

A resistência à compressão média das lajes da ETE foi de 51,7 MPa (com desvio padrão de $\pm 5,6$ e coeficiente de variação de 10,7 \%) para uma idade de 20 anos do concreto, aproximadamente, sendo que o valor apresentado já contempla a correção em função da relação altura/diâmetro $(\mathrm{h} / \mathrm{d})\left(\mathrm{k}_{1}\right)$ e do efeito do broqueamento em função do diâmetro do testemunho $\left(\mathrm{k}_{2}\right)$ de acordo com a norma NBR 7680-1 [14].

A ETE possuía uma resistência à compressão de projeto de aproximadamente $22 \mathrm{MPa}$ e no trabalho de Hoppe Filho et al. [15] os autores observaram uma resistência de $42 \mathrm{MPa}$, que assim como no presente estudo, está bem acima do projeto. É importante ressaltar que na época de construção da ETE, na norma NBR 6118 do ano de 1980 não havia restrição em relação à resistência à compressão mínima e/ou relação água/cimento máxima para concretos submetidos a ambientes agressivos.

Desde modo, apesar da degradação acentuada superficial e da presença de etringita ao longo de toda a profundidade do concreto das lajes, provenientes do ataque por ácido sulfúrico biogênico, o comportamento mecânico se manteve. 
GODINHO, J. P.; MEDEIROS; M. H. F., DEGRADAÇÃO DO CONCRETO ARMADO POR ÁCIDO SULFÚRICO BIOGÊNICO DO REATOR RALF DE UMA UMA ESTAÇÃO DE TRATAMENTO DE ESGOTO (ETE). $4^{\circ}$ Simpósio Paranaense de Patologia das Construções (40 SPPC), artigo 4SPPC128, pp. 261 - 270, 2019. DOI: 10.4322/2526-7248.048

\section{Conclusões}

Em relação a primeira parte do trabalho que consistiu na caracterização da degradação do concreto armado da ETE, foi possível tirar as seguintes conclusões:

- $\mathrm{O} \mathrm{pH}$ do interior das lajes se manteve acima da faixa de viragem da solução de fenolftaleína $(8,2 \leq \mathrm{pH} \leq 10,0)$, mesmo após 20 anos de ataque ácido na sua superfície;

- Nos aspectos visuais, as paredes e as lajes dos reatores possuem várias extensões de armaduras expostas e intensamente corroídas, com descamação e manchas de ferrugem, que pelo ensaio de potencial de corrosão apontou valores abaixo de $-500 \mathrm{mV}$ (em relação ao eletrodo de referência de cobre-sulfato de cobre) para todas elas;

- Apesar da degradação acentuada do concreto, as suas características mecânicas se mantiveram preservadas, com a resistência à compressão ainda maior do que a observada na última inspeção a 5 anos atrás por Hoppe et al. [15];

- A análise de MEV/EDS possibilitou identificar o acúmulo de gipsita nas amostras da parte externa do testemunho e acúmulo de etringita ao longo da profundidade em todas as fatias da parte interna do testemunho extraído da laje do reator RALF da ETE.

\section{Agradecimentos}

Os autores expressam a sua gratidão as agências brasileiras CNPq, Capes e Fundação Araucária pela bolsa e apoio financeiro, bem como a Universidade Federal do Paraná (UFPR) câmpus Curitiba, Centro Politécnico, ao Departamento de Construção Civil (DCC), ao Programa de Pós-Graduação em Engenharia de Construção Civil (PPGECC), ao Centro de Estudos de Engenharia Civil (CESEC), ao Laboratório de Materiais e Estruturas (LAME), ao Centro de Microscopia Eletrônica (CME), ao Laboratório de Óptica de Raios X e Instrumentação (LORXI), a Companhia de Saneamento do Paraná (SANEPAR) e ao grupo de pesquisa de Patologia e Recuperação das Construções (PRC).

\section{Referências}

[1] Chernicharo, C.A.L. (2013) Reactores Anaerobios: Série Princípios del tratamiento biológico de aguas residuales, $1^{\text {a }}$, Editorial Universitaria, Universidad de Nariño, San Juan de Pasto.

[2] Monteny, J.; De Belie, N.; Taerwe, L. (2003) Resistance of different types of concrete mixtures to sulfuric acid. Materials and Structures. 36:242-249.

[3] De Belie, N., Monteny, J.; Beeldens, A.; Vincke, E.; Van Gemert, D.; Verstraete, W. (2004) Experimental research and prediction of the effect of chemical and biogenic sulfuric acid on different types of commercially produced concrete sewer pipes, Cement and Concrete Research. 34:2223-2236. 
[4] Vincke, E. (2001) Biogenic sulfuric acid corrosion of concrete: microbial interaction, simulation and prevention. Ph.D. Thesis, 218p. Faculty of Agricultural and Applied Biological Sciences, Ghent University, Ghent, Belgium.

[5] O'Connell, M.; McNally, C.; Richardson, M.G. (2012) Performance of concrete incorporating GGBS in aggressive wastewater environments. Construction and Building Materials. 27:368-374.

[6] O'Connell, M.; McNally, C.; Richardson, M.G. (2010) Biochemical attack on concrete in wastewater applications: A state of the art review. Cement and Concrete Composites. 32:479-485.

[7] Herisson, J.; van Hullebusch, E.D.; Moletta-Denat, M.; Taquet, P., Chaussadent, T. (2013) Toward an accelerated biodeterioration test to understand the behavior of Portland and calcium aluminate cementitious materials in sewer networks, International Biodeterioration and Biodegradation. Elsevier, 84:236-243.

[8] BS EN 14630 (2006) Products and systems for the protection and repair of concrete structures - Test methods - Determination of carbonation depth in hardened concrete by the phenolphthalein method. British Standards Institute BSI.

[9] RILEM CPC-18 (1994) Measurement of hardened concrete carbonation depth. Materials and Structures. International Union of Laboratories and Experts in Construction Materials - RILEM.

[10] ASTM C876 (2015) Standard Test Method for Corrosion Potentials of Uncoated Reinforcing Steel in Concrete. American Society For Testing And Materials ASTM, West Conshohocken, PA, USA.

[11] Capraro, A.P.B.; Gervasio, S.; Medeiros, M.H.F.; Hoppe Filho, J.; Braganca, M.; Oliveira, I. (2016) Avaliação dos mecanismos de corrosão de concretos contaminados com diferentes teores de pirita (FeS2), in: An. do $58^{\circ}$ Congresso Brasileiro de Concreto (58 CBC 2016), Instituto Brasileiro do Concreto IBRACON, Belo Horizonte/MG, pp. 1-16.

[12] Souza, L.R. de A.; Medeiros, M.H.F. de; Pereira, E.; Capraro, A.P.B. (2017) Electrochemical chloride extraction: Efficiency and impact on concrete containing $1 \%$ of $\mathrm{NaCl}$. Construction and Building Materials. 145:435-444.

[13] NBR 5739 (2018) Ensaio de compressao em corpos-de-prova cilindricos. Associação Brasileira de Normas Técnicas - ABNT, Rio de Janeiro, Brasil.

[14] NBR 7680-1 (2019) Concreto - Extração, preparo, ensaio e análise de testemunhos de estruturas de concreto Parte 1: Resistência à compressão axial. Associação Brasileira de Normas Técnicas - ABNT, Rio de Janeiro, Brasil.

[15] Hoppe Filho, J.; Rheinheimer, B.; Khoe, S.S.; Artigas, L. V.; Sabbag, A.F.; Medeiros, M.H.F. (2014) Degradação do concreto de uma Estação de Tratamento de Esgoto (ETE) por ácido sulfúrico biogênico, Revista ALCONPAT. 4:87-99.

[16] NBR 6118 (1980) Projeto de estruturas de concreto - Procedimento. Associação Brasileira de Normas Técnicas - ABNT, Rio de Janeiro, Brasil. 